\title{
PARKINSON'S AWARE IN PRIMARY CARE: THE LATEST GUIDELINES
}

\author{
Isabel Huggett, Consultant Physician \\ Westmorland General Hospital
}

I last wrote about Parkinson's disease in this journal in 1993 and there have been changes in drug therapy since then. The latest guidelines produced by the Parkinson's Disease Society are a useful guide to the appropriate management of Parkinson's disease at various stages with pertinent reminders. I am proud to say that Audrey Stainton, the Parkinson's Disease Nurse Specialist, currently employed for the Kendal District and Furness, has been a member of the task force which produced the guidelines. They were circulated to all GPs in November 1998 and further copies are enclosed with this journal.

I would like to highlight a few points and helpful hints.

\section{DIAGNOSIS}

Parkinson's disease is a clinical diagnosis and can be difficult. There are many syndromes and conditions which have similarities or common features with Parkinson's disease. I recommend a review in the British Medical Journal for further reading ${ }^{(1)}$.

\section{LEVODOPA AND DYSKINESIA}

There is no doubt that levodopa frequently produces motor fluctuations and dyskinesias after five years of treatment ${ }^{(2)}$. The worst affected patients are those receiving large intermittent doses of levodopa and those with a young age at onset of the disease. There is concern from animal studies that even a single dose of levodopa could prime patients with Parkinson's Disease for the development of dyskinesia in the future. The previous practice of a therapeutic trial of levodopa should, therefore, be avoided in young patients, and the young elderly. There is a consensus that dopamine agonists are the most suitable treatment in younger patients but for symptomatic reasons, such as very severe bradykinesia or rigidity, there may be no alternative to levodopa. There is an ongoing debate about the relative risks and benefits of levodopa in the elderly. The decision to start levodopa or a dopamine agonist as the initial treatment depends on life expectancy and co-morbid conditions. A 65-year-old who is otherwise fit should receive a dopamine agonist first but a 90 -year-old with severe symptoms would be best treated with levodopa. The majority of patients are less clear-cut and need careful consideration. Dopamine agonists are not as effective as levodopa at relieving symptoms $^{(3)}$, are more difficult to titrate and are less well tolerated than levodopa, especially in the confused elderly. They need careful titration and monitoring for side effects. Treatment with domperidone, starting two days before initiation of treatment, helps to prevent nausea and postural hypotension. Don't rush in with treatment without considering carefully whether the diagnosis is correct and what is the best treatment in the longterm for that particular patient.

\section{COMT INHIBITORS}

COMT inhibitors (Tolcapone and Entacapone) are only useful with levodopa and cannot be used as monotherapy. They smooth out fluctuations but are not helpful in patients with dyskinesia. Diarrhoea was a major side effect with Tolcapone, which has recently been withdrawn because of concerns about liver damage. Entacapone is about to be launched and studies suggest this is likely to cause fewer side effects, including diarrhoea. Frequent monitoring of liver function will be required, although studies have not shown liver toxicity.

\section{DOMPERIDONE}

Domperidone is a dopamine antagonist which does not cross the blood brain barrier and is the only suitable drug for nausea and vomiting in Parkinson's disease. It is especially helpful if the nausea is precipitated by medication. It is also useful for drug-induced postural hypotension at a dose of $10-20 \mathrm{mg}$ tds. Patients with Parkinson's disease frequently fall, sometimes due to dizziness, so check blood pressure when lying and standing.

\section{RESTLESS LEGS}

This causes misery, especially at night, in later stages of the disease. Controlled release levodopa at bedtime may help. Amitriptyline, $10-25 \mathrm{mg}$ nocte is also useful but use the lowest possible dose.

\section{DEPRESSION}

Tricyclics and some of the SSRI's can exacerbate Parkinson's disease. Sertraline is a dopamine reuptake blocker and does not worsen Parkinson's symptoms so is the drug of choice in Parkinson's disease patients with depression.

\section{SURGERY}

Thalamotomy for tremor and pallidotomy for dyskinesia can have dramatic results but the risk of complications such as hemiparesis or aphonia are very real. Surgery should only be considered for patients with a firm diagnosis of idiopathic Parkinson's disease and failure to respond to medication. Referral should be by a consultant to a specialised centre, after careful assessment.

\section{SUPPORT FOR PATIENTS AND CARERS}

There are national and local Parkinson's Disease Society groups which are listed in Table 1.

Audrey Stainton is available for advice to health professionals, patients and carers. 


\begin{tabular}{|c|c|}
\hline $\begin{array}{l}\text { Parkinson's Disease Society } \\
\text { of the United Kingdom } \\
215 \text { Vauxhall Bridge Road } \\
\text { London SW1V 1EJ } \\
01719318080\end{array}$ & $\begin{array}{l}\text { Parkinson's Disease Society } \\
\text { Lancaster \& Morecambe } \\
\text { Branch } \\
\text { Mrs Jackie Syson } \\
01524732473\end{array}$ \\
\hline $\begin{array}{l}\text { Parkinson's Disease Society } \\
\text { Kendal Branch } \\
\text { Mrs Monica Tarring } \\
01539625252 \\
\text { Parkinson's Disease Society } \\
\text { Furness Group } \\
\text { Mr Ron Cowling } \\
01229462014\end{array}$ & $\begin{array}{l}\text { Parkinson's Disease } \\
\text { Specialist Nurse } \\
\text { Mrs Audrey Stainton } \\
\text { Dunmail Day Hospital } \\
\text { Westmorland General Hospital } \\
\text { Kendal } \\
01539795265 \\
\text { Mobile } 0378325829\end{array}$ \\
\hline
\end{tabular}

Table 1 - Sources of support and information

\section{REFERENCES}

1 Quinn N Parkinsonism - recognition and differential diagnosis Br Med J 1995;310:447-452

2 Marsden CD, Parkes JD Success and problems of long term levodopa therapy in Parkinson's disease Lancet 1977;i:345-349

3 Rinne UK, Bracco F, Chouza C, Dupont E, Gershanik O, Marti-Masso JF et al Cabergoline in the treatment of early Parkinson's disease Neurology 1997;48(2):363-368.

\section{Lancaster and Westmorland Medical Journal Prize}

The editorial board has not awarded the prize for 1998, but encourages all doctors in training grades to submit original work for the 1999 award. 